\title{
Relevance of Calcium and Vitamin D in Supporting Bone Health: An Expert Panel Recommendation in Indonesia
}

\author{
Saptawati Bardosono ${ }^{1, ~ *, ~ A n d o n ~ H e s t i a n t o r o ~}{ }^{2}$, Andri Maruli Tua Lubis ${ }^{3}$, Siti Setiati ${ }^{4}$, \\ Ani Retno Prijanti ${ }^{5}$, Purwantyastuti ${ }^{6}$, Luciana Sutanto ${ }^{7}$, Maria Regina Rachmawati ${ }^{8}$, Sheryl Tan ${ }^{9}$ \\ ${ }^{1}$ Department of Nutrition, Faculty of Medicine, University of Indonesia / Cipto Mangunkusumo Hospital, Jakarta, Indonesia \\ ${ }^{2}$ Department of Obstetrics \& Gynecology, University of Indonesia / Cipto Mangunkusumo Hospital, Jakarta, Indonesia \\ ${ }^{3}$ Department of Orthopaedic Faculty of Medicine, Universitas Indonesia / Cipto Mangunkusumo Hospital, Jakarta, Indonesia \\ ${ }^{4}$ Department of Internal Medicine Faculty of Medicine, Universitas Indonesia / Cipto Mangunkusumo Hospital, Jakarta, Indonesia \\ ${ }^{5}$ Department Biochemistry and Molecular Biology, Faculty of Medicine, Universitas Indonesia, Jakarta, Indonesia \\ ${ }^{6}$ Department of Pharmacology, Faculty of Medicine, Universitas Indonesia / Cipto Mangunkusumo Hospital, Jakarta, Indonesia \\ ${ }^{7}$ Department of Nutrition, Universitas Kristen Kr, Jakarta, Indonesia \\ ${ }^{8}$ Faculty of Medicine, Universitas Gunadarma / Pasar Minggu Municipal Hospital, Jakarta, Indonesia \\ ${ }^{9}$ Medical \& Clinical Development, Bayer Consumer Care, Singapore
}

\section{Email address:}

tati.bardo@yahoo.com (S. Bardosono), hestiantoro@gmail.com (A. Hestiantoro), andri_lubis@yahoo.com (A. M. T. Lubis), siti.setiati@gmail.com (S. Setiati), aniretno@gmail.com (A. R. Prijanti), purwanty2703@yahoo.com (Purwantyastuti), lcsutanto@yahoo.com (L. Sutanto), rachmawatidr@gmail.com (M. R. Rachmawati), shery.tan@bayer.com (S. Tan)

${ }^{*}$ Corresponding author

\section{To cite this article:}

Saptawati Bardosono, Andon Hestiantoro, Andri Maruli Tua Lubis, Siti Setiati, Ani Retno Prijanti, Purwantyastuti, Luciana Sutanto, Maria Regina Rachmawati, Sheryl Tan. Relevance of Calcium and Vitamin D in Supporting Bone Health: An Expert Panel Recommendation in Indonesia. International Journal of Nutrition and Food Sciences. Vol. 9, No. 2, 2020, pp. 54-62. doi: 10.11648/j.ijnfs.20200902.13

Received: August 22, 2019; Accepted: April 23, 2020; Published: May 14, 2020

\begin{abstract}
Osteoporosis is a bone health related condition that weakens the bones, making individuals fragile and prone to breaks. Nutrients such as calcium and vitamin $\mathrm{D}$ are essential for bone health. Calcium helps in building and maintaining bone mass while vitamin D aids in the absorption and utilization of calcium. According to WHO, $28.8 \%$ men and $32.3 \%$ women in Indonesia have osteoporosis, and this is inspite of the international recommendations for the daily intake of calcium and vitamin D intake. This could be attributed to low community awareness on how to prevent and care for osteoporosis. Several high-risk population groups have been identified such as those with osteopenia, undergoing rehabilitation and pregnancy/lactation periods. Therefore, in this review, an expert panel comprising of specialties of dietetics, rehabilitation medicine, orthopaedic, obstetrics \& gynaecology, pharmacology, and geriatrics, convened to provide an evidence-based guidance on the prevention and care for osteoporosis. The recommendations are as follows: (i) It is important to know that calcium and vitamin D work synergistically to maintain bone health. (ii) The intake of calcium and vitamin D must start early. (iii) We should be aware that our diet and lifestyle today does not allow us to meet the recommended daily intake of calcium and vitamin D required for optimal bone health. (iv) Supplementation can compensate for the deficits in both calcium and vitamin D intake, thereby strengthening bone health. This study could guide the primary health care team, who plays a critical role in community care, to encourage early bone health awareness and care in Indonesia.
\end{abstract}

Keywords: Calcium, Vitamin D, Indonesia, Supplement, Osteoporosis, Pregnancy

\section{Introduction}

The skeletal system comprises of bones and connective tissues, and is important in protecting our organs and muscles, supporting the production of new blood cells, and regulating calcium homeostasis [1]. Bone health is 
increasingly important with age, as older adults experience bone loss, which increases the risk of bone fractures [2]. One condition that weakens the bones, making them fragile and prone to breaks is osteoporosis. This condition builds up over a period gradually, not visible until the individual experiences a fall or sudden impact. Causes of osteoporosis is primarily due to loss of bone density with age and occurs at different rates based on multifactorial reasons. Examples include gender, longterm use of certain medication such as steroids, comorbidities, genetics, lifestyle and diet [3]. Besides osteoporosis, pregnancy and breastfeeding periods also put extra demand on women's bone health. During pregnancy, the fetus depends on the maternal calcium store to develop its skeleton, especially so in the last trimester. Subsequently, during breastfeeding, the baby continues to draw calcium from the mother's bones. Bone loss during pregnancy and breastfeeding is usually recovered after the period ends. However, the incidence of osteoporosis during pregnancy/breastfeeding is possible [4]. Related to the prevention and management of osteoporosis, rehabilitation periods are also critical [5]. Rehabilitation refers to the restoration of health post injury or illness and is required to restore muscle and bone strength. Success of rehabilitation in osteoporotic and fractured individuals have improved their overall quality of life [6].

In Asia, osteoporosis is one of the most prevalent and costly health problems, where socio-economic advancements are coupled with a rapidly ageing population [7]. Taking Indonesia as a key example, the Indonesia Osteoporosis Society (PEROSI) estimates that about $41.8 \%$ of Indonesian men and $90 \%$ of Indonesian women were osteopenic (lowered bone mineral density), whereas $28.8 \%$ of men and $32.3 \%$ of women had osteoporosis according to WHO criteria. The Indonesian Ministry of Health has acknowledged osteoporosis as a major health problem since 2006 [8]. To support this endeavor, this article aims to review the role of nutrition in bone health and provide recommendations to improve awareness on building bone health in Indonesia.

\section{Methods}

An expert panel group consisted of a multidisciplinary consortium of seven experts across specialties including obstetrician-gynecologist, medical rehabilitation specialist internist, orthopedic \& traumatologist, clinical nutritionist, pharmacologist as well as biomedical \& molecular biologist from Indonesia. An advisory board meeting was convened in Indonesia in March 2019 to deliberate on evidence-based recommendations pertaining to the role of calcium and vitamin $\mathrm{D}$ in bone health. The panel also shared their clinical experiences specific to the Indonesian population. All information was gathered and summarized in this publication. The views here do not represent the opinion of any national or international societies.

\section{Recommendations from the Expert Panel}

\subsection{Calcium and Vitamin D Work Synergistically to Maintain Bone Health}

Calcium is one of the most important elements in the human body, wherein, $99 \%$ of calcium is stored in the skeleton as hydroxyapatite which provides skeletal (bone) strength, and around 1\% of calcium is in the blood, soft tissues and extracellular fluid. It is a vital component of bone architecture and is required for deposition of bone mineral throughout life [9]. Some of the natural sources of food items rich in calcium includes milk, yogurt, cheese, soymilk, tofu, kale etc [10]. Notably, intracellular calcium is also an important second messenger that is involved in a wide range of physiological roles such as muscle contraction, cellular motility, fertilization, cell growth or proliferation, neurogenesis, synaptic plasticity as well as learning and memory [11]-[13]. Also, during pregnancy, calcium plays a vital role. The main period of skeletal mineralization of the fetus starts during the third trimester of pregnancy. In this period, the increased fetal demand for calcium is met by maternal calcium stores $[14,15]$. This results in a reduction in total calcium concentration in pregnant women, which could possibly increase the risk of pregnancy-induced onset of osteoporosis [16, 17].

Vitamin D is a fat-soluble vitamin which is converted to calcidiol [25 $(\mathrm{OH}) \mathrm{D}$; vitamin D2] in the liver, and then converted to calcitriol (1,25- dihydroxycholecalciferol; vitamin D3) which is the biologically active form of vitamin $\mathrm{D}$ involved in the absorption of calcium in the small intestine $[9,18]$. Some of the natural sources of food items containing vitamin D include; oily fish, fortified milk, egg yolk, cheese etc. Vitamin D, in concert with peptide hormones such as parathyroid hormone (PTH) and calcitonin, mediates calcium and phosphorous metabolism at target tissues, including bone, intestine and kidney [19]. Other roles of vitamin D includes optimization and maintenance of bone mineral density (BMD) $[20,21]$ and improvement of muscle strength [22]. Without sufficient intake of vitamin $\mathrm{D}$, there could be dearth of calcitriol, ergo, insufficient absorption of calcium [23, 24].

The respective biological roles of calcium and vitamin D in our body suggests that both nutrients work together to protect the bones - calcium helps build and maintain bones and vitamin D helps in effective absorption of calcium. This synergy has been demonstrated to reduce the risk of osteoporosis [25].

The American Food and Nutrition Board (FNB) established recommended dietary allowances (RDA) for calcium and vitamin D for bone health, subcategorized by age, gender or for pregnant, or lactating women $[10,26]$. Table 1 consolidates information on the RDA of calcium and vitamin $\mathrm{D}$ as per the International Osteoporosis foundation (IOF) benchmarked against FNB. The daily intakes recommended by the Indonesian Healthy Bone Foundation (PERWATUSI) [27] refers to IOF and as shown in table 1, 
both FNB and IOF guidelines are similar, demonstrating the consistency in the need for both calcium and Vitamin D intake across all age groups and conditions. It is recommended that intake of calcium increases with age for both men and women. Also, for women aged 51-70 years old, there is a higher recommended intake of calcium compared to men of the same age i.e. $1200 \mathrm{mg}$ for women versus 1000 $\mathrm{mg}$ for men respectively. Recommendations for vitamin D intake also increases with age for both men and women, similar to that of calcium intake. As described by their biological roles and recommended daily intakes by international guidelines, both calcium and vitamin $\mathrm{D}$ are critical and synergistic in building bone health, eventually preventing osteoporosis in later life.

Table 1. Calcium and vitamin D nutrition adequacy rate as per international recommendations.

\begin{tabular}{|c|c|c|c|c|c|}
\hline & & \multicolumn{2}{|l|}{ FNB $[10,26]$} & \\
\hline \multirow{13}{*}{$\begin{array}{l}\text { Calcium } \\
\text { (mg/day) }\end{array}$} & & \multicolumn{2}{|c|}{ Infancy to adolescence } & \multicolumn{2}{|l|}{ IOF [28, 29] } \\
\hline & $0-6$ months & \multicolumn{2}{|c|}{$200 \mathrm{mg}$} & \multicolumn{2}{|l|}{-} \\
\hline & 7- 12 months & \multicolumn{2}{|l|}{$260 \mathrm{mg}$} & \multicolumn{2}{|l|}{-} \\
\hline & $1-3$ years & \multicolumn{2}{|l|}{$700 \mathrm{mg}$} & \multicolumn{2}{|l|}{$700 \mathrm{mg}$} \\
\hline & $4-8$ years & \multicolumn{2}{|l|}{$1,000 \mathrm{mg}$} & \multicolumn{2}{|l|}{$1,000 \mathrm{mg}$} \\
\hline & $9-13$ years & \multicolumn{2}{|l|}{$1,300 \mathrm{mg}$} & \multicolumn{2}{|l|}{$1,300 \mathrm{mg}$} \\
\hline & 14- 18 years & \multicolumn{2}{|l|}{$1,300 \mathrm{mg}$} & \multicolumn{2}{|l|}{$1,300 \mathrm{mg}$} \\
\hline & & Male & Female & Male & Female \\
\hline & 19- 50 years & $1,000 \mathrm{mg}$ & $1,000 \mathrm{mg}$ & $1,000 \mathrm{mg}$ & $1,000 \mathrm{mg}$ \\
\hline & $51-70$ years & $1,000 \mathrm{mg}$ & $1,200 \mathrm{mg}$ & $1,000 \mathrm{mg}$ & $1,200 \mathrm{mg}$ \\
\hline & Pregnant/lactation $14-18$ years old & & $1,300 \mathrm{mg}$ & & $1,300 \mathrm{mg}$ \\
\hline & Pregnant/lactation $19-50$ years old & & $1,000 \mathrm{mg}$ & & $1,000 \mathrm{mg}$ \\
\hline & $71+$ years & $1,200 \mathrm{mg}$ & $1,200 \mathrm{mg}$ & $1,200 \mathrm{mg}$ & $1,200 \mathrm{mg}$ \\
\hline & & Male & Female & Male & Female \\
\hline & $>70$ years & $800 \mathrm{IU}(20 \mathrm{mcg})$ & $800 \mathrm{IU}(20 \mathrm{mcg})$ & $800 \mathrm{IU}(20 \mathrm{mcg})$ & $800 \mathrm{IU}(20 \mathrm{mcg})$ \\
\hline
\end{tabular}

* IOF recommendations for adults aged 60 years and over are 800 to $1000 \mathrm{IU} /$ day for falls and fracture protection

\subsection{Intake of Calcium and Vitamin D Must Start Early}

Establishing the vital roles of calcium and vitamin D in bone health, the authors also recommended an early intake of these nutrients. Current literature has demonstrated the prevalence of low levels of calcium and vitamin D among Indonesians today [36-43]. Deficiency of calcium at infancy/childhood not only increases the risk of skeletal problems in the future, but could also lead to nutritional rickets or osteomalacia among children, the consequences of which could be lethal or persist into adulthood [30]-[32].

During puberty and adolescence, the calcium requirement is higher, due to accelerated muscular, skeletal and endocrine development. About $95 \%$ of young women's peak bone mass is present by age 20 and overall gain continues often until age 30. Adequate intake of calcium and vitamin $\mathrm{D}$ during this period of life helps to achieve peak bone density [33, 34]. A study in Indonesia showed that $40.6 \%$ of Indonesian women aged 20-29 years had a low peak bone mass, indicating that a higher proportion of women could face the risk of fractures in the next 20 years when they reach menopause, which is the typical onset of decreased bone mass and an increased risk of osteoporosis. This study also showed that lower levels of calcium intake during childhood or adolescence, calculated using the historical calcium index (HCI), could potentially influence the peak bone mass of women. This demonstrates that lower consumption of calcium in childhood and early adulthood is one of the key determinants of low peak bone mass [35].

With regards to vitamin D, a SEANUT study showed prevalence of low levels of vitamin D in comparison to WHO standards among pre-school and school-aged children in Indonesia [36]. Another study showed similar results; high prevalence of vitamin D insufficiency in healthy children aged 7-12 years in Indonesia [37]. Vitamin D insufficiency is a health problem among Indonesian children, wherein the level of vitamin $\mathrm{D}$ in teenagers was found at the minimum level of $15 \mathrm{ng} / \mathrm{dL}$ [38]. According to the National Institute of Health standards, the vitamin D level in blood should be at least $20 \mathrm{ng} / \mathrm{mL}$ [26].

Aside from adequate intake of calcium and vitamin D at early stages of life (puberty \& adolescence), pregnancy and lactation also require high calcium intake. A recent review on nutritional uptake in pregnant women reported low average intake of calcium among women in Indonesia [39]. This corresponded to another research by IOF that found low dietary calcium intake among the general population in Asian countries including Indonesia [40]. There is also a higher prevalence of vitamin D deficiency and insufficiency among pregnant women compared to non-pregnant counterparts in Indonesia [41]. A study which assessed the rate of bone health decline and incidence rate of osteoporosis in several Asian countries demonstrated that the T-mean score of women decreased dramatically with ageing and was the lowest for Indonesia, indicating that osteoporosis could be a major problem in the near future [42].

The current literature above has suggested there is low intake of both calcium and vitamin $\mathrm{D}$ among Indonesians today. This low intake may occur in childhood or during pregnancy and persist in later life, manifesting as 
osteoporosis-related problems. Therefore, early intake of both calcium and vitamin $\mathrm{D}$ are essential to prevent the buildup of related medical conditions, which are irreversible.

\subsection{Diet and Lifestyle May Hinder Meeting the Daily Recommended Intake of Calcium and Vitamin D}

The intake of calcium and vitamin $\mathrm{D}$ is negatively impacted by diet and/or lifestyle-related factors such as reduced exposure to sun, lack of physical activity and obesity $[43,44]$. Based on the international standards i.e. FNB or IOF the recommended daily allowances of calcium ranges between 1000-1200 mg/day for adults [45]. A study in 2010 revealed that the average calcium intake of the Indonesian people reached only $254 \mathrm{mg} /$ day. One of the possible reasons cited was the lower consumption of calcium rich foods or cooking methods which resulted in significant loss of nutrient intake [46].

There is an established association of vitamin D deficiency with lifestyle, for example, women who spent significant time indoors, avoiding sun rays, sunblock application, and low physical activity have a higher likelihood of vitamin D deficiency [48-50]. These lifestyle factors are common among Indonesian women [47]. A study on Indonesian women of childbearing age working as female garment workers, revealed that those women who wore veil had a higher risk of vitamin D deficiency compared to workers who did not wear veil [49]. Consequently, a study in North Sumatra, Indonesia, showed that the mean vitamin D level in women was $17.1 \mathrm{ng} / \mathrm{mL}$, which was far below the normal serum level for a country with sufficient sun exposure [48].

There is also a positive association between higher physical activity outdoors and vitamin D levels [50]. A Spanish study showed that $82 \%$ of Spanish indoor athletes had suboptimal levels of plasma vitamin D concentration, suggesting that outdoor physical activities increases plasma vitamin D concentration [51, 52]. A US study conducted by Sragg and Camargo using the US National Health and Nutrition Examination Survey (NHANES III) found that the association between physical activity and vitamin D was stronger in outdoor compared to indoor environments [53]. Additionally, a Dutch longitudinal cross-sectional study showed that serum 25-hydroxyvitamin D (25-OHD) below $20 \mathrm{ng} / \mathrm{ml}$ was associated with poor physical performance among older men and women [54].

Dionyssiotis et al. also showed that physical activity and adequate dietary calcium intake was indicated as means to maximize bone status benefits for women [55]. Additionally, there have been studies demonstrating association between physical activity (regardless of sunlight exposure) and BMD. For example, a cochrane review indicated a protective effect of exercise on bone density in post-menopausal women in comparison with control groups [56]. A Canadian study also demonstrated that a step increase in the amount of daily activity, using simple, daily performed tasks, can help prevent BMD decrease in post-menopausal women [57].

High level of fat in adipose tissue which affects health is defined as obesity. Obesity can be calculated by measuring the body mass index (BMI). Studies have shown that with a higher level of body fat, the serum level of calcidiol will be lower. Since vitamin D is deposited in the adipocyte cells and is difficult to transport for circulation, the serum levels of calcidiol is low [47]. This was also observed in a South-east Asian study, whereby, in Indonesians, higher BMI was associated with a lower calcidiol levels [58].

Overall, we have collated evidence pertaining to the impact of lifestyle, physical activity and obesity on calcium and vitamin $\mathrm{D}$ intake, all pointing to the direction that our diet and lifestyle today may not allow us to meet the daily recommended intake of calcium and vitamin $\mathrm{D}$. These critical factors in the Indonesian cohort need to be further addressed with relevant country-wide initiatives.

\subsection{Supplementation can Compensate for Deficits in the Daily Recommended Intake of Calcium and Vitamin D}

With the possible avenues leading to deficits in the recommended dietary intake of calcium and vitamin $\mathrm{D}$, one may opt for supplementation to fill the gaps [25]. There has been increasing evidences over the years on how supplementation in adequate proportion supports health outcomes [59]. For example, calcium supplementation reduces bone turnover by $20 \%$ and was associated with a reduction in postmenopausal bone loss [60]. A study in Thailand has also showed a decrease in bone turnover and prevention of bone loss among elderly women who were supplemented with calcium [61]. Interestingly, there was also prevention of clinical fractures among elderly who were compliant on calcium supplementation relative to those with poor compliance [62]. With respect to pregnancy, studies also showed that maternal skeletal remodeling could be reduced by means of calcium supplementation [63, 64]. A randomized crossover trial of calcium supplementation on bone resorption among pregnant women by Vanitha et al. showed that $1200 \mathrm{mg}$ of calcium supplementation during third trimester of pregnancy reduces maternal bone skeletal turnover [63]. Additionally, a Cochrane review of 13 trials reported that the average risk of pre-eclampsia was reduced among those receiving calcium supplementation [64].

Vitamin D supplementation prevents hip fractures among elderly persons [65]. A meta-analysis of randomized controlled trials on prevention of fractures with vitamin D supplementation showed that vitamin D supplementation in the range of 700-800 IU reduced the risk of hip fractures and any non-vertebral fractures among the elderly [66]. Studies also showed benefits of vitamin D supplementation on fall prevention among older individuals [22, 67]. A systematic review and meta-analysis study further revealed an additive effect of physical exercise and vitamin D3 supplementation on the improvement of muscle strength among older adults [68]. Additionally, prenatal multivitamin supplementation helped to raise the serum $25(\mathrm{OH}) \mathrm{D}$ (calcidiol; vitamin D2) level among childbearing age women with high prevalence of vitamin D insufficiency [69].

Supplementation of combined calcium plus vitamin D supports the prevention of osteoporosis and subsequent 
fractures among the older population [70]-[74]. Daily intake of calcium and vitamin D supplementation was found to have a positive effect on the skeleton of ambulatory postmenopausal women [75]. Chapuy et al. showed that supplementation with vitamin D3 and calcium reduces the risk of hip fractures among elderly women [76]. Decalyos-II, a double-masked, placebo-controlled trial showed that calcium (1200 mg) and vitamin D3 (800 IU) in combination reduced both hip bone loss and the risk of hip fracture among elderly women [RR $1.69(95 \% \mathrm{CI}=0.96,3.0)]$ compared to the placebo group. Besides this, other studies such as Decalyos-I and the Dawson-Hughes et al. study have also established effects of combined calcium and vitamin D3 supplementation on the prevention of fracture risk [77].

Overall, current literature have clearly demonstrated the benefits of calcium, vitamin D and combined calciumvitamin $\mathrm{D}$ supplementation in meeting gaps in daily requirement, more so in (i) preventing pre-eclampsia during pregnancy, and (ii) osteoporosis prevention among elderly $[64,70]-[72]$. More research is warranted to further define the benefits of calcium and vitamin D supplementation for pregnancy care and osteoporosis prevention.

Nevertheless, despite evidence emphasizing the benefits of supplementation, there are a couple of watch-outs prior to intake. Firstly, it is important to note the lower and upper tolerable intake limits of each nutrient. Over intake of calcium and/or vitamin D could have negative consequences as these are fat-soluble nutrients, reinforcing the importance of guideline recommendations of tolerable limit. For example, inconclusive evidence have suggested high calcium intake may increase the risk of prostate cancer [78]. Preliminary studies have also suggested an association of high calcium levels with elevated risk of kidney stones [79]. Similarly for vitamin $\mathrm{D}$, a study showed that intake of high doses of vitamin D (cholecalciferol 500,000 IU) in older women was associated with more falls and fractures [80]. Also, the source and amount of calcium per intake needs to be considered too. Most calcium supplements provide calcium via either one of the two sources of elemental calcium: calcium carbonate or calcium citrate. Calcium carbonate is absorbed best when taken with food, while calcium citrate is absorbed well on an empty or a full stomach. Notably, calcium absorption is best when a person consumes no more than $500 \mathrm{mg}$ at a time. So a person who takes $1000 \mathrm{mg} /$ day of calcium from supplements is advised to split the dose rather than take it all at once [10]. All in all, prior to taking calcium and vitamin D supplements, we need to take extra consideration on total amount taken, source of calcium and the amount per intake.

\section{Conclusion}

Overall, the literature on the FNB and IOF guidelines demonstrated the importance of both calcium and vitamin D in protecting and maintaining bone health, by recommending increased intake of both nutrients with age. This is scientifically well supported by the known synergistic roles of calcium and vitamin D in our bodies, with calcium helping to build and maintain bones and vitamin D helping in the effective absorption of calcium. This synergy has been demonstrated to reduce the risk of osteoporosis [25]. In Indonesia, this could be emphasized and potentially introduced to all healthcare practitioners, particularly in the primary care community. One way to achieve this could be to provide a consensus guidance document, initiated by professional organizations such as Ikatan Dokter Indonesia (IDI), with the endorsement of ministry of health (MOH) for implementation to the general population.

With emphasis on the study that highlights $40.6 \%$ of Indonesian women aged 20-29 years had a low peak bone mass, indicates that these women could face the risk of fractures in the next 20 years when they reach menopause, which is the typical onset of decreased bone mass and an increased risk of osteoporosis. This relatively high percentage of Indonesian women with low peak bone mass could be attributed to low calcium consumption during late childhood and early adulthood. With reference to the SEANUT study, there is also low levels of vitamin D in comparison to WHO standards among pre-school and schoolaged children in Indonesia. Exposure to morning sunlight is the common practice amongst parents of newborn until around 2-4 years of age. However, this practice stops as soon as children reach pre-school age (4 years and above), largely due to the environment. Parents try to keep children indoors to minimize exposure to air pollution and drastic temperature changes, thereby limiting their daily exposure to sunlight. Dietary habits such as the intake of processed food also contributes to low vitamin D level. Vitamin D levels in our body can be met with sufficient exposure to morning sunlight, accompanied by adequate outdoor exercises. Efforts need to be put in the future, to increase this awareness in parents.

Supplementation in adequate proportion can support positive outcomes in bone health [59]. Current literature have clearly demonstrated the benefits of calcium, vitamin D and combined calcium-vitamin D supplementation in meeting gaps in daily requirement [64, 70]-[72]. In Indonesia, calcium supplementation has always been regarded mainly for young children, pregnant women and elderly. The purpose of consuming calcium supplements relates to helping children grow strong teeth and achieve heights, and for elderly to prevent osteoporosis. Overall, the awareness to build up calcium repository from childhood up until adulthood is low. There is a potential gap here that could be addressed with continued efforts to educate the community via healthcare professionals.

Lastly, in this review, we focused on healthy individuals going through various life stages such as childhood, adulthood, pregnancy and old age, however, some limitations could be noted. More discussion and research is potentially required for individuals with existing and/or underlying health conditions such as hypertension and diabetes. In these individuals, care for their bone health needs to be further tailored by their healthcare professionals, taking into account their lifestyle and environment. Additionally, there is also a need for an increased understanding of the benefits and 
watch-outs of supplementation, with more discussion and research relevant towards Indonesian population.

In conclusion, early and adequate intake of calcium and vitamin $\mathrm{D}$, alongside lifestyle modifications and appropriate supplementation could contribute towards strong bone health in Indonesia. In this journey, healthcare professionals could be important guiding lights to assess nutrient deficiencies and associated risks. In the future, interventions could be best initiated within the primary care communities, which has frequent touchpoints with the general population.

Table 2 summarizes the key recommendations and accompanying literature to support.

Table 2. Key recommendations.

\begin{tabular}{|c|c|}
\hline Recommendations & Available evidences \\
\hline \multirow{5}{*}{$\begin{array}{l}\text { Calcium and vitamin } \mathrm{D} \text { work synergistically to } \\
\text { maintain bone health }\end{array}$} & 1) Ilich JZ et al. Eur J Clin Nutr. 2003. 57 (4): 554-65. \\
\hline & 2) Chen LR et al. International Journal of Gerontology. 2014. 8: 183-188 \\
\hline & 3) Von Domarus et al. Clin Orthop Relat Res. 2011.469 (11): 3127-3133 \\
\hline & 4) Kyoung M K et al. J Clin Endocrinol Metab. 2014.99 (7): 2409-2417 \\
\hline & 5) Beaudart C et al. J Clin Endocrinol Metab. 2014.99 (11): 4336-45 \\
\hline \multirow{4}{*}{ Intake of calcium and vitamin D must start early } & 1) Setiarsih D et al. Makara J. Health Res. 2016. 20 (3): 63-68 \\
\hline & 2) Sugianto R et al. Jurnal Gizi Klinik Indonesia 2014.11 (2): 78-84 \\
\hline & 4) C. F. Munns et al. J Clin Endocrinol Metab. 2016.101: 394-415 \\
\hline & 5) Uday, S. \& Högler, W. et al. Curr Osteoporos Rep.201.15: 293 \\
\hline \multirow{6}{*}{$\begin{array}{l}\text { Our diet and lifestyle today may not allow us to meet } \\
\text { the daily recommended intake of calcium and vitamin } \\
\text { D }\end{array}$} & 1) Scragg R et al. Am J Epidemiol. 2008.168 (6): 577-86 \\
\hline & 2) Dionyssiotis et al. BMC Women's Health. 2010. 10: 12 \\
\hline & 3) Howe TE et al. Cochrane Database Syst Rev. 2011. (7): CD000333 \\
\hline & 4) Wicherts IS, et al. J Clin Endocrinol Metab. 2007. 92: 2058-65 \\
\hline & 5) Valtueña J et al. Nutr Hosp. 2014. 30 (1): 124-31 \\
\hline & 6) Wanner M et al. Cancer Causes Control. 2015. 26 (6): 881-91. \\
\hline \multirow{14}{*}{$\begin{array}{l}\text { Supplementation can compensate for the deficits in the } \\
\text { daily recommended intake of calcium and vitamin D }\end{array}$} & 1) Hacker AN et al. Nutrition Reviews Vol. 2012. 70 (7): 397-409 \\
\hline & 2) Avenell A et al. Cochrane Database Syst Rev. 2014. 4: CD000227 \\
\hline & 3) Weaver CM et al. Ostéoporoses Int. 2016.27 (1): 367-76 \\
\hline & 4) Bischoff-Ferrari et al. N Engl J Med. 2012.367 (1): 40-9 \\
\hline & 5) Bischoff-Ferrari HA et al. JAMA. 2005. 293: 2257-e2264 \\
\hline & 6) Antoniak A et al. BMJ Open. 2017. 7 (7): e014619 \\
\hline & 7) John A Sunyecz. Ther Clin Risk Manag. 2008. 4 (4): 827-836 \\
\hline & 8) Jackson RD et al. N Engl J Med. 2006. 16; 354 (7): 669-83 \\
\hline & 9) Tang BM et al. Lancet. 2007. 370 (9588): 657-66 \\
\hline & 10)Prince RL et al. Arch Intern Med. 2006. 166 (8): 869-75 \\
\hline & 11)Harwood RH et al. Age Ageing. 2004.33 (1): 45-51 \\
\hline & 12)Chapuy MC et al. Osteoporos Int. 2002. 13 (3): 257-64 \\
\hline & 13)Rajatanavin R et al. Osteoporos Int. 2013.24 (11): $2871-7$ \\
\hline & 14) Bischoff-Ferrari HA et al. Am J Clin Nutr. 2008.87 (6): 1945-51 \\
\hline
\end{tabular}

\section{Acknowledgements}

This manuscript was developed by Dr Shikha Singh from Kantar, Health Division, following an expert panel meeting supported by Bayer South East Asia, Ltd in March 2019.

\section{References}

[1] B. campus Open text, " 6.1 The Functions of the Skeletal System - Anatomy and Physiology." [Online]. Available: https://opentextbc.ca/anatomyandphysiology/chapter/6-1-thefunctions-of-the-skeletal-system/. [Accessed: 07-May-2019].

[2] "Johns Hopkins Bayview News - The Importance of Bone Health." [Online]. Available: https://www.hopkinsmedicine.org/news/publications/jh_bayvi ew_news/summer_2013/the_importance_of_bone_health. [Accessed: 07-May-2019].

[3] “Osteoporosis," nhs.uk, 03-Oct-2018. [Online]. Available: https://www.nhs.uk/conditions/osteoporosis/. [Accessed: 07May-2019].
[4] "Pregnancy, Breastfeeding and Bone Health | NIH Osteoporosis and Related Bone Diseases National Resource Center." [Online]. Available: https://www.bones.nih.gov/health-info/bone/bonehealth/pregnancy. [Accessed: 07-May-2019].

[5] "Osteoporosis in Rehabilitation." [Online]. Available: https://www.aapmr.org/about-physiatry/conditionstreatments/musculoskeletal-medicine/osteoporosis-inrehabilitation. [Accessed: 07-May-2019].

[6] Y. Dionyssiotis, G. Skarantavos, and P. Papagelopoulos, "Modern Rehabilitation in Osteoporosis, Falls, and Fractures," Clin. Med. Insights Arthritis Musculoskelet. Disord., vol. 7, pp. 33-40, Jun. 2014.

[7] E. M. C. Lau, "Osteoporosis-a worldwide problem and the implications in Asia.," Ann. Acad. Med. Singapore, vol. 31, no. 1, pp. 67-68, 2002.

[8] “Asian_regional_audit_Indonesia.pdf.".

[9] "Vitamin D, calcium homeostasis and aging." [Online]. Available: https://www.ncbi.nlm.nih.gov/pmc/articles/PMC5068478/. [Accessed: 22-Apr-2019]. 
[10] "Office of Dietary Supplements - Calcium." [Online]. Available: $\quad$ https://ods.od.nih.gov/factsheets/CalciumHealthProfessional/. [Accessed: 16-Apr-2019].

[11] M. Brini, T. Calì, D. Ottolini, and E. Carafoli, "Intracellular calcium homeostasis and signaling," Met. Ions Life Sci., vol. 12, pp. 119-168, 2013.

[12] E. Carafoli and J. Krebs, "Why Calcium? How Calcium Became the Best Communicator," J. Biol. Chem., vol. 291, no. 40, pp. 20849-20857, Sep. 2016.

[13] M. P. Blaustein, "Intracellular Calcium as a Second Messenger," in Calcium in Biological Systems, R. P. Rubin, G. B. Weiss, and J. W. Putney, Eds. Boston, MA: Springer US, 1985, pp. 23-33.

[14] S. Mohammad-Alizadeh-Charandabi, M. Mirghafourvand, A. Mansouri, M. Najafi, and F. Khodabande, "The Effect of Vitamin D and Calcium plus Vitamin D during Pregnancy on Pregnancy and Birth Outcomes: a Randomized Controlled Trial," J. Caring Sci., vol. 4, no. 1, pp. 35-44, Mar. 2015.

[15] E. M. Curtis, R. J. Moon, E. M. Dennison, and N. C. Harvey, "Prenatal Calcium and Vitamin D Intake, and Bone Mass in Later Life," Curr. Osteoporos. Rep., vol. 12, no. 2, pp. 194 204, Jun. 2014.

[16] A. J. Phillips, S. J. Ostlere, and R. Smith, "Pregnancy-associated osteoporosis: does the skeleton recover?," Osteoporos. Int. J. Establ. Result Coop. Eur. Found. Osteoporos. Natl. Osteoporos. Found. USA, vol. 11, no. 5, pp. 449-454, 2000.

[17] F. Dunne, B. Walters, T. Marshall, and D. A. Heath, "Pregnancy associated osteoporosis," Clin. Endocrinol. (Oxf.), vol. 39, no. 4, pp. 487-490, Oct. 1993.

[18] "Calcium and Vitamin D: Skeletal and Extraskeletal Health." [Online].

Available: https://www.ncbi.nlm.nih.gov/pmc/articles/PMC2669834/. [Accessed: 22-Apr-2019].

[19] R. Boland, "Role of Vitamin D in Skeletal Muscle Function," Endocr. Rev., vol. 7, no. 4, pp. 434-448, Nov. 1986.

[20] W. B. Grant and M. F. Holick, "Benefits and Requirements of Vitamin D for Optimal Health: A Review," Vitam. D, vol. 10, no. 2, p. 18, 2005.

[21] K. M. Kim et al., "Interactions Between Dietary Calcium Intake and Bone Mineral Density or Bone Geometry in a Low Calcium Intake Population (KNHANES IV 2008-2010)," J. Clin. Endocrinol. Metab., vol. 99, no. 7, pp. 2409-2417, Jul. 2014.

[22] O. Bruyère et al., "Effects of vitamin D in the elderly population: current status and perspectives," Arch. Public Health, vol. 72, Sep. 2014.

[23] "Bone and nutrition in elderly women: protein, energy, and calcium as main determinants of bone mineral density. PubMed - NCBI." [Online]. Available: https://www.ncbi.nlm.nih.gov/pubmed/12700617. [Accessed: 22-Apr-2019].

[24] R. Rizzoli et al., "The role of dietary protein and vitamin D in maintaining musculoskeletal health in postmenopausal women: A consensus statement from the European Society for Clinical and Economic Aspects of Osteoporosis and Osteoarthritis (ESCEO)," Maturitas, vol. 79, no. 1, pp. 122-132, Sep. 2014.

[25] J. A. Sunyecz, "The use of calcium and vitamin D in the management of osteoporosis," Ther. Clin. Risk Manag., vol. 4, no. 4, pp. 827-836, Aug. 2008.

[26] "Office of Dietary Supplements - Vitamin D." [Online]. Available: https://ods.od.nih.gov/factsheets/VitaminDHealthProfessional/. [Accessed: 17-Apr-2019].

[27] "Nutrition Improvement." [Online]. Available: http://www.perwatusi.or.id/index.php/id/kenali-keropostulang/pencegahan/perbaikan-gizi. [Accessed: 14-Jun-2019].

[28] “Calcium | International Osteoporosis Foundation.” [Online]. Available: https://www.iofbonehealth.org/osteoporosismusculoskeletal-disorders/osteoporosis/prevention/calcium. [Accessed: 13-May-2019].

[29] "Vitamin D | International Osteoporosis Foundation." [Online]. Available: https://www.iofbonehealth.org/osteoporosismusculoskeletal-disorders/osteoporosis/prevention/vitamin-d. [Accessed: 13-May-2019].

[30] T. O. Carpenter, N. J. Shaw, A. A. Portale, L. M. Ward, S. A. Abrams, and J. M. Pettifor, "Rickets," Nat. Rev. Dis. Primer, vol. 3, p. 17101, Dec. 2017.

[31] C. F. Munns et al., "Global Consensus Recommendations on Prevention and Management of Nutritional Rickets," J. Clin. Endocrinol. Metab., vol. 101, no. 2, pp. 394-415, Feb. 2016.

[32] S. Uday and W. Högler, "Nutritional Rickets and Osteomalacia in the Twenty-first Century: Revised Concepts, Public Health, and Prevention Strategies," Curr. Osteoporos. Rep., vol. 15, no. 4, pp. 293-302, 2017.

[33] A. L. Bueno and M. A. Czepielewski, "The importance for growth of dietary intake of calcium and vitamin D," J. Pediatr. (Rio J.), vol. 84, no. 5, pp. 386-394, Oct. 2008.

[34] "Healthy Bones at Every Age - OrthoInfo - AAOS." [Online]. Available: https://www.orthoinfo.org/en/staying-healthy/healthybones-at-every-age/. [Accessed: 13-May-2019].

[35] R. Sugianto, J. Titus, and M. Siagian, "Risk factors of low peak bone mass in Indonesian women," J. Gizi Klin. Indones., vol. 11, no. 2, pp. 78-84, Oct. 2014.

[36] S. Sandjaja et al., "Food consumption and nutritional and biochemical status of 0.5-12-year-old Indonesian children: the SEANUTS study," Br. J. Nutr., vol. 110 Suppl 3, pp. S11-20, Sep. 2013.

[37] F. Soesanti, A. Pulungan, B. Tridjaja, and J. R. Batubara, "Vitamin D profile in healthy children aged 7-12 years old in Indonesia," Int. J. Pediatr. Endocrinol., vol. 2013, no. Suppl 1, p. P167, 2013.

[38] "Universitas Gadjah Mada: Indonesian Children Susceptible to Vitamin D Deficiency." [Online]. Available: http://ugm.ac.id/en/news/16274indonesian.children.susceptible.to.vitamin.d.deficiency. [Accessed: 23-Apr-2019].

[39] Y. Hartriyanti, P. S. T. Suyoto, H. F. L. Muhammad, and I. R. Palupi, "Nutrient intake of pregnant women in Indonesia: a review," Malays. J. Nutr., vol. 18, no. 1, pp. 113-124, Apr. 2012.

[40] For the International Osteoporosis Foundation Calcium Steering Committee et al., "Global dietary calcium intake among adults: a systematic review," Osteoporos. Int., vol. 28, no. 12, pp. 3315-3324, Dec. 2017.

[41] “(PDF) Bone Density Status and Vitamin D and Calcium 
Concentrations in Pregnant and Non-Pregnant Women." [Online]. Available: https://www.researchgate.net/publication/311630339_Bone_D ensity_Status_and_Vitamin_D_and_Calcium_Concentrations in_Pregnant_and_Non-Pregnant_Women. [Accessed: 22A $\overline{\text { pr-2019]. }}$.

[42] M. C. Kruger and F. M. Wolber, "Osteoporosis: Modern Paradigms for Last Century's Bones," Nutrients, vol. 8, no. 6, Jun. 2016

[43] N. E. Koundourakis and A. N. Margioris, "Vitamin D and Physical Activity," Crit. Eval. Vitam. - Basic Overv., Apr. 2017.

[44] "THE GLOBAL EPIDEMIOLOGY OF VITAMIN D STATUS • JARCP The Journal of Aging Research \& Clinical Practice." [Online]. Available: http://www.jarcp.com/703-theglobal-epidemiology-of-vitamin-d-status.html. [Accessed: 13May-2019].

[45] K. R. Dewi, E. M. Hidayat, and A. Rachmawati, "Knowledge, Attitude, and Behavior Level of Women of Reproductive Age toward Calcium Intake," Althea Med. J., p. 5.

[46] C. Wariyah, M. Astuti, S. Supriyadi, and C. Anwar, "CALCIUM ABSORPTION KINETIC ON INDONESIAN RICE," Indones. J. Chem., vol. 8, no. 2, pp. 252-257, Jun. 2010 .

[47] "Indonesian women - 95 percent do not have sufficient Vitamin D - Nov 2017 |." [Online]. Available: https://vitamindwiki.com/Indonesian+women+\%E2\%80\%93+ $95+$ percent + do + not + have + sufficient + Vitamin $+\mathrm{D}+\% \mathrm{E} 2 \% 80 \%$ 93+Nov+2017. [Accessed: 17-Apr-2019].

[48] D. Sari, D. Harun Alrasyid, L. Nurlndrawaty, and L. Zulkif Ii, "Occurrence of vitamin D deficiency among women in North Sumatera, Indonesia," Malays. J. Nutr., vol. 20, pp. 63-70, Jan. 2014.

[49] “(PDF) Is vitamin D defiiency associated with using veil in female garment workers?" [Online]. Available: https://www.researchgate.net/publication/304671112_Is_vita min_D_defiiency_associated_with_using_veil_in_female_gar ment_workers. [Accessed: 22-Apr-2019].

[50] M. Wanner, A. Richard, B. Martin, J. Linseisen, and S. Rohrmann, "Associations between objective and self-reported physical activity and vitamin D serum levels in the US population," Cancer Causes Control CCC, vol. 26, no. 6, pp. 881-891, Jun. 2015.

[51] M. R. Fernandes, "Association between physical activity and vitamin D: A narrative literature review," Rev Assoc Med Bras, p. 7.

[52] J. Valtueña, D. Dominguez, L. Til, M. González-Gross, and F. Drobnic, "High prevalence of vitamin D insufficiency among elite Spanish athletes the importance of outdoor training adaptation," Nutr. Hosp., vol. 30, no. 1, pp. 124-131, Jul. 2014.

[53] R. Scragg and C. A. Camargo, "Frequency of leisure-time physical activity and serum 25-hydroxyvitamin D levels in the US population: results from the Third National Health and Nutrition Examination Survey," Am. J. Epidemiol., vol. 168, no. 6, pp. 577-586; discussion 587-591, Sep. 2008.

[54] I. S. Wicherts et al., "Vitamin D status predicts physical performance and its decline in older persons," J. Clin.
Endocrinol. Metab., vol. 92, no. 6, pp. 2058-2065, Jun. 2007.

[55] Y. Dionyssiotis, I. Paspati, G. Trovas, A. Galanos, and G. P. Lyritis, "Association of physical exercise and calcium intake with bone mass measured by quantitative ultrasound," $B M C$ Womens Health, vol. 10, p. 12, Apr. 2010.

[56] T. E. Howe et al., "Exercise for preventing and treating osteoporosis in postmenopausal women," Cochrane Database Syst. Rev., no. 7, p. CD000333, Jul. 2011.

[57] J. M. Muir, C. Ye, M. Bhandari, J. D. Adachi, and L. Thabane, "The effect of regular physical activity on bone mineral density in post-menopausal women aged 75 and over: a retrospective analysis from the Canadian multicentre osteoporosis study," BMC Musculoskelet. Disord., vol. 14, p. 253, Aug. 2013.

[58] B. K. Poh et al., "25-hydroxy-vitamin D demography and the risk of vitamin D insufficiency in the South East Asian Nutrition Surveys (SEANUTS).," Asia Pac. J. Clin. Nutr., vol. 25, no. 3, pp. 538-548, 2015.

[59] H. A. Bischoff-Ferrari, J. R. Rees, M. V. Grau, E. Barry, J. Gui, and J. A. Baron, "Effect of calcium supplementation on fracture risk: a double-blind randomized controlled trial," Am. J. Clin. Nutr., vol. 87, no. 6, pp. 1945-1951, Jun. 2008.

[60] I. R. Reid, "Should We Prescribe Calcium Supplements For Osteoporosis Prevention?," J. Bone Metab., vol. 21, no. 1, pp. 21-28, Feb. 2014.

[61] R. Rajatanavin, L. Chailurkit, S. Saetung, A. Thakkinstian, and H. Nimitphong, "The efficacy of calcium supplementation alone in elderly Thai women over a 2-year period: a randomized controlled trial," Osteoporos. Int. J. Establ. Result Coop. Eur. Found. Osteoporos. Natl. Osteoporos. Found. USA, vol. 24, no. 11, pp. 2871-2877, Nov. 2013.

[62] R. L. Prince, A. Devine, S. S. Dhaliwal, and I. M. Dick, "Effects of calcium supplementation on clinical fracture and bone structure: results of a 5-year, double-blind, placebocontrolled trial in elderly women," Arch. Intern. Med., vol. 166, no. 8, pp. 869-875, Apr. 2006.

[63] V. Janakiraman, A. Ettinger, A. Mercado-Garcia, H. Hu, and M. Hernandez-Avila, "Calcium supplements and bone resorption in pregnancy: A randomized crossover trial," Am. $J$. Prev. Med., vol. 24, no. 3, pp. 260-264, Apr. 2003.

[64] A. N. Hacker, E. B. Fung, and J. C. King, "Role of calcium during pregnancy: maternal and fetal needs," Nutr. Rev., vol. 70, no. 7, pp. 397-409, Jul. 2012.

[65] H. A. Bischoff-Ferrari et al., "A pooled analysis of vitamin D dose requirements for fracture prevention," N. Engl. J. Med., vol. 367, no. 1, pp. 40-49, Jul. 2012.

[66] H. A. Bischoff-Ferrari, W. C. Willett, J. B. Wong, E. Giovannucci, T. Dietrich, and B. Dawson-Hughes, "Fracture prevention with vitamin D supplementation: a meta-analysis of randomized controlled trials," JAMA, vol. 293, no. 18, pp. 2257-2264, May 2005.

[67] R. H. Harwood, O. Sahota, K. Gaynor, T. Masud, D. J. Hosking, and Nottingham Neck of Femur (NONOF) Study, "A randomised, controlled comparison of different calcium and vitamin D supplementation regimens in elderly women after hip fracture: The Nottingham Neck of Femur (NONOF) Study," Age Ageing, vol. 33, no. 1, pp. 45-51, Jan. 2004. 
[68] P. Dewansingh, A. Melse-Boonstra, W. P. Krijnen, C. P. van der Schans, H. Jager-Wittenaar, and E. G. H. M. van den Heuvel, "Supplemental protein from dairy products increases body weight and vitamin D improves physical performance in older adults: a systematic review and meta-analysis," Nutr. Res. N. Y. N, vol. 49, pp. 1-22, 2018.

[69] A. A. Ginde, A. F. Sullivan, J. M. Mansbach, and C. A. Camargo, "Vitamin D insufficiency in pregnant and nonpregnant women of childbearing age in the United States," Am. J. Obstet. Gynecol., vol. 202, no. 5, pp. 436. e1-436. e8, May 2010.

[70] A. Avenell, J. C. Mak, and D. O'Connell, "Vitamin D and vitamin D analogues for preventing fractures in post menopausal women and older men," Cochrane Database Syst. Rev., no. 4, 2014.

[71] C. M. Weaver et al., "Calcium plus vitamin D supplementation and risk of fractures: an updated metaanalysis from the National Osteoporosis Foundation," Osteoporos. Int., vol. 27, pp. 367-376, 2016.

[72] H. A. Bischoff-Ferrari, S. Bhasin, and J. E. Manson, "Preventing Fractures and Falls: A Limited Role for Calcium and Vitamin D Supplements?," JAMA, vol. 319, no. 15, pp. 1552-1553, Apr. 2018.

[73] R. D. Jackson et al., "Calcium plus vitamin D supplementation and the risk of fractures," N. Engl. J. Med., vol. 354, no. 7, pp. 669-683, Feb. 2006.

[74] B. M. P. Tang, G. D. Eslick, C. Nowson, C. Smith, and A. Bensoussan, "Use of calcium or calcium in combination with vitamin D supplementation to prevent fractures and bone loss in people aged 50 years and older: a meta-analysis," Lancet Lond. Engl., vol. 370, no. 9588, pp. 657-666, Aug. 2007.

[75] M. Kärkkäinen et al., "Effect of calcium and vitamin D supplementation on bone mineral density in women aged 65 71 years: a 3-year randomized population-based trial (OSTPRE-FPS)," Osteoporos. Int., vol. 21, no. 12, pp. 2047 2055, Dec. 2010.

[76] M. C. Chapuy et al., "Vitamin D3 and Calcium to Prevent Hip Fractures in Elderly Women," N. Engl. J. Med., vol. 327, no. 23, pp. 1637-1642, Dec. 1992.

[77] M. C. Chapuy et al., "Combined calcium and vitamin D3 supplementation in elderly women: confirmation of reversal of secondary hyperparathyroidism and hip fracture risk: the Decalyos II study," Osteoporos. Int. J. Establ. Result Coop. Eur. Found. Osteoporos. Natl. Osteoporos. Found. USA, vol. 13, no. 3, pp. 257-264, Mar. 2002.

[78] "Prostate Cancer \& Calcium Concerns." [Online]. Available: https://www.oncologynutrition.org/erfc/eating-well-whenunwell/prostate-cancer-calcium-concerns. [Accessed: 24-Apr2019].

[79] "Calcium and Vitamin D Supplements May Increase Stone Risk," Renal and Urology News, 29-Jun-2012. [Online]. Available: https://www.renalandurologynews.com/home/news/urology/kidn ey-stones/calcium-and-vitamin-d-supplements-may-increasestone-risk/. [Accessed: 24-Apr-2019].

[80] K. M. Sanders et al., "Annual High-Dose Oral Vitamin D and Falls and Fractures in Older Women: A Randomized Controlled Trial," JAMA, vol. 303, no. 18, pp. 1815-1822, May 2010. 